\title{
The effect of diagnostic label on care staff's perceptions of cause of challenging behaviour in individuals with learning disabilities
}

Article

Accepted Version

Gifford, C. and Knott, F. (2016) The effect of diagnostic label on care staff's perceptions of cause of challenging behaviour in individuals with learning disabilities. British Journal of Learning Disabilities, 44 (4). pp. 322-328. ISSN 1468-3156 doi: https://doi.org/10.1111/bld.12171 Available at https://centaur.reading.ac.uk/69293/

It is advisable to refer to the publisher's version if you intend to cite from the work. See Guidance on citing.

Published version at: http://onlinelibrary.wiley.com/doi/10.1111/bld.12171/full

To link to this article DOI: http://dx.doi.org/10.1111/bld.12171

Publisher: Wiley

All outputs in CentAUR are protected by Intellectual Property Rights law, including copyright law. Copyright and IPR is retained by the creators or other copyright holders. Terms and conditions for use of this material are defined in the End User Agreement. 


\section{CentAUR}

Central Archive at the University of Reading

Reading's research outputs online 
Staff perception of challenging behaviour.

The Effect of Diagnostic Label on Care Staff's Perceptions of Cause of Challenging Behaviour in People with Learning Disabilities

\title{
Accessible Summary
}

- We wanted to know what care staff felt about difficult behaviour displayed by people with autism, learning disabilities or Down syndrome.

- We asked many care staff who worked with people with disabilities to watch a video. The video was about a made up lady called Sophie. Sometimes Sophie was described as having autism, other times as having learning disabilities and sometimes as having Down syndrome.

- After staff members watched the video we asked them how they felt about Sophie's difficult behaviour.

- Staff viewed Sophie's behaviour better when she was described as having autism and worst when she was described as having learning disabilities.

- We believe that staff should view all people equally regardless of the way they are described. We have used the information about this study to make recommendations about staff training.

\section{Keywords}

Autism, Down syndrome, learning (intellectual) disabilities, staff training.

\begin{abstract}
Background: This study investigated whether care staff's causal attributions and emotional reactions to the challenging behaviour displayed by service users was influenced by the service user's diagnostic label.

Materials and Method: One hundred and twenty care staff were randomly allocated to one of three conditions. Participants viewed a video of a senior staff member describing a service user, varying only in diagnostic label (autism, learning disability or Down syndrome). Participants then rated their endorsement of possible causes and emotional reactions to challenging behaviour.
\end{abstract}


Staff perception of challenging behaviour.

Results: Participants in the Autism and Down syndrome groups made more use of biomedical causes and less use of learned behaviour as an explanation for challenging behaviour than those in the Learning Disabilities group. Those in the former groups reported more positive and fewer negative emotions than those in the Learning Disabilities group.

Conclusions: The way staff viewed people with learning disabilities was affected by their diagnostic label. Implications for further research and training has been discussed.

\section{Introduction}

Local Authorities in the UK reported that 140,015 adults with learning disabilities known to them, live in accommodation where some form of care is provided (Public Health England, 2013). In addition, 114,265 adults with learning disabilities are supported in social care community services (Public Health England, 2013). Challenging behaviour is displayed by $10 \%$ of people with learning disabilities (Lowe, Allen, Jones, Brophy, Moore \& James, 2007) and is associated with a range of negative outcomes for these individuals including reduced access to leisure, education and employment (Bubb, 2014). Behaviour can be described as challenging when it is of such an intensity, frequency or duration as to threaten the quality of life and/or the physical safety of the individual or others and is likely to lead to responses that are restrictive, aversive or result in exclusion (Banks, Bush \& Baker, 2007). For care staff, the emotional impact of challenging behaviour in terms of both stress and burn out is significant (Mills \& Rose, 2011). Further, abuse and neglect from care staff towards people with learning disabilities may contribute to the development of challenging behaviour (Hastings, 1997a; Bubb, 2014). The need to understand staff perceptions of and responses to challenging behaviour is therefore 
Staff perception of challenging behaviour.

paramount. A considerable body of work now focuses on care staff's emotional responses and causal attributions of challenging behaviour (Dagnan, Trower \& Smith, 1998; Dagnan \& Cairns, 2005; Lucas, Collins \& Langdon, 2009). Such attributions may help to illuminate aspects of care staff behaviour such as willingness to engage in evidence based interventions (Rose, 2011). A better understanding of causal attributions and emotional reactions may therefore assist in the development of high quality service provision and improved staff training, reducing placement breakdown and leading to better outcomes for both care staff and service users with learning disabilities.

The dominant paradigm in research investigating causal attributions made by staff working with people with learning disabilities is Weiner's (1985) cognitive model of helping behaviour (Willner \& Smith, 2008). In this model, attributions about the cause of behaviour elicit emotions in the observer which then determine their willingness to help the person (Weiner, 1985). While there is support for this model in the general population, application to people with learning disabilities has proved less consistent (Willner \& Smith, 2008). Methodological reasons such as reliance on vignettes (Lucas et al. 2009) and poor consensus over the definition of helping behaviour (Willner \& Smith, 2008) may in part explain this inconsistency. However, other causal explanations, such as those identified by Hastings (1997b) may also influence staff attributions. These factors include learned behaviour, medical/biological factors, emotional factors, the physical environment and self-stimulation (Hastings, 1997b).

Research has started to tease out some of the variables that might mediate attributions made about people with learning disabilities. Staff who are rated high on 
Staff perception of challenging behaviour.

expressed emotion are more likely to see challenging behaviour as internal and controllable (Willner \& Smith, 2008), as are younger staff (Wanless \& Jahoda, 2002). Women with learning disabilities are more likely to be ascribed internal causes for their challenging behaviour than men (Bromley \& Emerson, 1995) while staff are more likely to endorse biological causes for the challenging behaviour of people described as having 'severe' rather than 'mild' disabilities (Tynan \& Allen, 2002). Staff who perceive service users as independent are more likely to make attributions of control and to feel negatively about challenging behaviour (Stanley \& Standen, 2010). However, despite these advances in understanding the mediators of attributions, one area, the diagnostic label assigned to individuals has not yet been examined. This is an important omission because of the variation in understanding and stereotypes associated with learning disabilities (Gibbs \& Thorpe, 1983).

Labels given to individuals who display challenging behaviour have been shown to affect both attributions and emotional response towards them (Link, Cullen, Struening, Shrout \& Dohrenwend, 1989). Markham and Trower (2003) found that psychiatric nurses ascribed controllable causes to hypothetical patients with borderline personality disorder and were less sympathetic to them, compared to patients described as having either depression or schizophrenia, conditions nurses appeared to construe as biological and uncontrollable. Similarly, undergraduates' affective responses were more positive and less negative towards social behaviours ascribed to either autism or schizophrenia compared to those with no label (Brosnan \& Mills, 2015). Despite the importance of labelling, no study has sought to investigate the effects of diagnostic labels on staff's causal attributions of challenging behaviour in learning disability settings. 
Staff perception of challenging behaviour.

The most common diagnostic terms used by care staff in UK learning disability services are autism, learning disabilities and Down syndrome (Carter, Capone, Gray, Cox \& Kaufmann, 2007; Emerson \& Baines, 2010). Learning disabilities is clinically and genetically heterogeneous and often has no known cause. For example, causal mutations in known developmental disability genes are only identifiable in 16 out of 100 people with learning disabilities (de Ligt, Willemsen, Van Bon, Kleefstra, Yntema, Kroes \& Vissers, 2012). Nonetheless, Battaglia and Carey (2003) estimated that $60 \%$ of people with learning disabilities have an additional comorbid diagnostic label linked to their learning disability. While Down syndrome is the most co-morbid diagnosis with learning disabilities (Carter et al. 2007) it is estimated that $20-33 \%$ of people with learning disabilities are on the autistic spectrum (Emerson \& Baines, 2010). As far as care staff are concerned, the terms autism and Down syndrome may convey information about causes compared to the more generic label of learning disabilities. This is particularly true in UK learning disability services where staff routinely describe co-morbid service users by their more established diagnostic labels such as autism or Down syndrome (i.e. as 'having autism'). In the context of attributions of cause of challenging behaviour, these more established labels may also elicit attributions about biological or uncontrollable causes which as predicted by Weiner's (1985) model, should elicit positive emotion. 
Staff perception of challenging behaviour.

\section{Aims of the present study}

The present study investigates the impact of diagnostic label on care staff's perception of causes of challenging behaviour. Firstly, it is predicted that staff will make more use of biological causes for the challenging behaviour of a person with autism and Down syndrome relative to someone with unspecified learning disabilities. Secondly, it is hypothesised that emotional responses will be endorsed differently, with negative emotions ascribed more often to someone with unspecified learning disabilities than to those with autism or Down syndrome.

\section{Method}

Ethical approval for this study (2011/70/FK) was granted by the University of Reading Research Ethics Committee on 19th August 2011.

The study utilised a between participants design with participants being randomly assigned to one of three groups; Autism, Down syndrome or Learning Disabilities. Forty participants were required in each condition to identify medium effect sizes (Cohen, 1992). Medium effect sizes were chosen arbitrarily to guide sample size given the lack of previously reported effect sizes in this field of study.

\section{Participants}

Operational Managers of three large private learning disability care service providers which serve the South of England promoted the study amongst their staff. Over 1,000 staff are employed by these providers and were informed about the study. Operational Managers disseminated the Information Sheet for Participants, Consent 
Staff perception of challenging behaviour.

Forms and Contact Details to their individual Home Managers who promoted the study in staff meetings.

One hundred and twenty staff volunteered and contributed to the study (age, $m=$ 36.62, $s d=11.43)$. The sample comprised 75 female and 45 male staff, reflecting the higher proportion of females in the care industry. Of the participants, $67 \%$ had between one and three years working in learning disability services. Forty percent reported no formal training in challenging behaviour, learning disabilities, autism or Down syndrome and $42 \%$ reported attending day courses on these topics.

\section{Measures}

Challenging Behaviour Attributions Scale [CHABA] Hastings (1997b). The CHABA measures endorsement of five causes of challenging behaviour: Biomedical (internal physical states), Learned Behaviour (positive and negative reinforcement processes), Stimulation (boredom/isolation), Physical Environment (aspects of the external environment) and Emotional (affect state). Participants indicated the likelihood of each item being a cause of challenging behaviour ( 0 = very unlikely; $1=$ unlikely; 2 = equally likely/unlikely; 3 = likely; 4 = very likely). Subscale scores were derived by averaging ratings comprising each subscale. The internal consistency of the CHABA subscales is good with Cronbach's alpha ranging from 0.65 to 0.87 (Hastings, 1997b).

Emotional Responses to Challenging Behaviour Scale [ERCBS] Jones \& Hastings (2003) was used to assess emotional reactions. The ERCBS comprises a list of 23 emotional reactions yielding four subscales, namely Depression/Anger (10); 
Staff perception of challenging behaviour.

Fear/Anxiety (5); Confident/Relaxed (4) and Cheerful/Excited (4). Participants were asked how they typically felt when people like the person described in the video displayed challenging behaviour. Participants rated the frequency of each emotion on a four point scale $(0=$ never; $1=$ yes, but infrequently; $2=$ yes, frequently; $3=$ very frequently). Subscale scores were derived by averaging ratings of the items comprising each subscale. The four subscales of the ERCBS have good internal consistency with Cronbach's Alpha values ranging from 0.69 to 0.86 (Jones \& Hastings, 2003).

\section{Procedure}

Participants completed the study in a quiet office in their work place at a time convenient to them which had been pre-agreed individually. Data collection was facilitated using a portable computer running E-Prime 2.0 software (Schneider, Eschman \& Zuccolotto, 2002). Following the study instructions, participants viewed the video and completed the questionnaires and demographic information. E-prime randomly varied the order of presentation of each individual item of each questionnaire. Participants were assigned to groups randomly by E-Prime.

\section{The Video}

The 44-second video showed a male senior staff member talking about a fictional character named Sophie, the challenging behaviour she had typically displayed and her diagnostic label. Videos were identical and only differed in the diagnostic label used to describe Sophie. The actor's words were taken from Tynan and Allen (2002, p- 215) who have validated this script in similar research involving care staff: - 
Staff perception of challenging behaviour.

"Hi, I am Sophie's Key Worker. Sophie is a young woman who has (autism, learning disabilities or Down syndrome). She lives in the community in a supervised setting with other adults with (autism, learning disabilities or Down syndrome). She is able to carry out some self-care tasks independently. However, she requires assistance from support staff to manage her financial affairs and aspects of her daily living. Sophie enjoys visiting the shops and travelling on local buses. Sometimes Sophie is aggressive towards the people who care for her and live with her. She will kick and punch people, pull their hair and physically push them, sometimes so forcefully that people fall to the ground. She can also rock and make loud repetitive noises at times".

\section{Results}

Staff characteristics

Across the three conditions there were no differences in staff mean age (36 years, 6 months), level of work related training or number of years working in learning disability services. There were more females than males in each of the three groups but the proportion of females was significantly higher in the Learning Disabilities group $\left[X^{2}(2)=7.89, p=.02\right]$. Percentages of female staff were $53 \%$ in the Autism group, $55 \%$ in the Down Syndrome group and $80 \%$ in the Learning Disabilities group. Table 1 shows the means and standard deviations of the measures by diagnostic label.

The effects of diagnostic label on endorsement of causes of Challenging Behaviour To test the hypothesis that the three groups would endorse different explanations for challenging behaviour, a between-subjects one-way ANOVA was carried out on each of the CHABA subscales. 
Staff perception of challenging behaviour.

Biomedical subscale. The ANOVA $\left[F(2,119)=10.69, p=.01\right.$, partial $\left.n^{2}=.15\right]$ and post hoc comparisons indicated that participants made significantly fewer Biomedical attributions in the Learning Disabilities group $(m=2.70, s d=.81)$ than in both the Autism ( $m=3.48, s d=.82)$ and Down Syndrome $(m=3.29, s d=.69)$ groups, who did not differ from each other.

Learned Behaviour subscale. ANOVA $\left[\mathrm{F}(2,117)=14.86, p=.01\right.$, partial $\left.n^{2}=.02\right]$ and post hoc comparisons showed that participants made more attributions about learned behaviour in the Learning Disabilities group $(m=3.65, s d=.98)$ than in both the Autism $(m=2.48, \mathrm{sd}=.87)$ and Down Syndrome $(m=2.99, \mathrm{sd}=1.02)$ groups who did not differ from each other.

The Stimulation, Physical Environment and Emotional subscales of the CHABA failed to reveal significant group differences.

The effects of diagnostic labels on emotional reactions to Challenging Behaviour To test the hypothesis that emotional reaction to challenging behaviour will be affected by diagnostic label, non-parametric statistics were used as the distributions of Depression/Anger and Confident/Relaxed scores showed a slight negative skew following a Kolmogorov-Smirnov test of normality. Fig.1 shows the pattern of results for the four subscales of the ERCBS divided into diagnostic group.

Kurskal-Wallis tests and follow up analyses revealed group differences $[h(2)=$ 15.14, $p=.01, n^{2}=12$ ] on Depression/Anger rank scores. The Learning Disabilities group endorsed Depression/Anger feelings more than the Autism group $[h(1)=$ 
Staff perception of challenging behaviour.

13.96, $p=.01, n^{2}=.17$ ] while the Learning Disabilities and Down Syndrome groups did not differ. The Autism group also endorsed fewer Depression/Anger feelings than the Down Syndrome group $\left[h(1)=5.40, p=.02, n^{2}=.06\right]$.

Similarly, the effect of label on Fear/Anxiety rank scores was significant $[h(2)=$ 16.05, $\left.p=.01, n^{2}=.13\right]$. The Learning Disabilities group endorsed more Fear/Anxiety feelings than the Autism $\left[h(1)=14.53, p=.01, n^{2}=.18\right]$ and Down Syndrome $\left[h(1)=4.22, p=.04, n^{2}=.05\right]$ groups. In turn, the Down Syndrome group endorsed more Fear/Anxiety feelings than the Autism group $\left[h(1)=5.37, p=.02, n^{2}\right.$ $=.06]$.

The effect of label on Cheerful/Excited rank scores was significant $[h(2)=7.41 p=$ $\left..25, n^{2}=.06\right]$. Cheerful/Excited emotions were endorsed less by the Learning Disabilities than by the Autism group [h $\left.(1)=3.99, p=.04, n^{2}=.05\right]$. There were no differences between the Learning Disabilities and Down Syndrome groups however the latter endorsed Cheerful/Excited feelings less than the Autism group $[h(1)=$ $\left.7.01, p=.01, n^{2}=.08\right]$

Finally, the effect of label on Confident/Relaxed rank scores was significant $[h(2)=$ $15.40 p=.01]$. The Learning Disabilities group endorsed less Confident/Relaxed emotions than the Autism group [ $\left.h(1)=9.60, p=.02, n^{2}=.12\right]$ but was no different to the Down Syndrome group. The latter endorsed fewer Confident/Relaxed emotions than the Autism group $\left[h(1)=13.10, p=.01, n^{2}=.16\right]$. 
Staff perception of challenging behaviour.

\section{Discussion}

The study showed that the diagnostic label ascribed to individual service users affected staff's causal attributions of a service user's challenging behaviour. Staff in the Autism and Down Syndrome groups made more use of biomedical causes to explain the challenging behaviour of a hypothetical service user than those in the Learning Disabilities group. In contrast, relative to those in the Learning Disabilities group, participants in the Autism and Down Syndrome groups considered the Learned Behaviour model to be of significantly less causal relevance. This finding is consistent with other research showing differential effects of labelling on staff attributions and emotional responses (Stanley \& Standen, 2000; Tynan \& Allen, 2002; Markham \& Trower, 2003).

This study also showed that diagnostic label affected emotions reported by care staff. Staff in the Autism and Down Syndrome groups reported more positive emotions and fewer negative emotions in response to challenging behaviour than the Learning Disabilities group. In particular, fewer feelings of depression, anger and anxiety were reported when the service user was described as having autism. Anxiety and fear were also reported less often within the Down Syndrome group compared to the Learning Disabilities group. The pattern of results for positive emotions was the opposite. Feelings of cheerfulness, excitement, confidence and relaxation were all endorsed more by staff in the Autism group compared to the other two groups while no differences for any of the positive emotions was found between the Down Syndrome and Learning Disabilities groups. 
Staff perception of challenging behaviour.

This study has implications for our understanding of staff treatment of people with different diagnostic labels. External and uncontrollable attributions, such as those that might result from biological causes, have been shown to be positively related to sympathy and inversely related to anger (Weiner, 1985). In the current study, there was higher endorsement of biological causes and higher agreement with positive emotions in the Autism than in the Learning Disabilities group. In contrast, in the Learning Disabilities group there was more endorsement of learned behaviour causal attributions, with more anxiety and fear than both the diagnostic groups and more depression and anger feelings than the Autism group. This supports Weiner's (1985) model, as learned behaviour is perceived as controllable by the person and therefore associated with negative emotion.

There were several possible explanations for these findings. Firstly, it was possible that care staff attributed the challenging behaviour of people with autism and Down syndrome to a biomedical cause in line with the genetic and organic nature of these conditions. In contrast, almost $40 \%$ of people with learning disabilities have no comorbid label (Battaglia \& Carey, 2003) and thus staff may have attributed challenging behaviour to learned behaviour as an alternative explanation. Secondly, people with autism and Down syndrome have well known behavioural or physical characteristics such as stereotypies in autism and facial features in Down syndrome (Gibbs \& Thorpe, 1983; Carter et al. 2007) and these may have reinforced the notion of organic causes in these groups as compared with the 'unspecified' Learning Disabilities group. Thirdly, media campaigns currently highlight people with autism more readily than other conditions, which may play a part in higher ratings of positive emotional responses to autism. Further research should examine the impact of 
Staff perception of challenging behaviour.

knowledge and stereotypes about learning disabilities on causal attributions and emotional responses to challenging behaviour.

The study had a number of limitations. The gender of the person in the video was kept constant but as internal causes for challenging behaviour are also more frequently ascribed to females than to males (Bromley \& Emerson, 1995), this may have affected the attributions made here. Similarly, the balance of male and female respondents was not equal across groups despite randomisation, with higher numbers of female staff in the Learning Disabilities group. Future research could compare causal attributions made about men and women by both male and female staff. Additionally, although the video methodology used here had advantages over vignettes, the use of hypothetical people affect the way care staff respond relative to real situations (Lucas et al. 2009).

\section{Conclusion}

This study demonstrated the impact of the diagnostic label on the emotional responses and causal attributions made by care staff about challenging behaviour. The implications for the service user-care staff relationship were significant, particularly in the context of high profiled cases of abuse from care staff towards service users highlighted in the media (Bubb, 2014). Support staff often work long and flexible hours as services are increasingly stretched, with a consequent detrimental effect on staff-service user relationships (Rose, 2011; Bubb, 2014). Therefore, advancing our understanding of the factors which may add strain to these already complex relationships will enhance our ability to support both the person with learning disabilities and the care staff who work alongside them. Training packages 
Staff perception of challenging behaviour.

need to take account of the impact of the diagnostic label, to correct misunderstanding and to allow staff to become aware of the role of the causal attributions they make towards challenging behaviour. Training should also be aimed at helping staff understand the people they are working with well, whether they have a diagnostic label or not. Together, these will contribute to a better working environment and enhanced quality of life for people with learning disabilities.

\section{References}

Banks, R., Bush, A., \& Baker, P. (2007). Challenging Behaviour: A Unified Approach, Royal College of Psychiatrists, British Psychological Society and Royal College of Speech and Language Therapists, London, CR 144.

Battaglia A. \& Carey J. C. (2003, February). Diagnostic evaluation of developmental delay/mental retardation: An overview. In American Journal of Medical Genetics Part C: Seminars in Medical Genetics (Vol. 117, No. 1, pp. 3-14). Wiley Subscription Services, Inc., A Wiley Company.

Bromley J. \& Emerson E. (1995). Beliefs and emotional reactions of care staff working with people with challenging behaviour. Journal of Intellectual Disability Research, 39, 341-352.

Brosnan M. \& Mills E. (2015). The effect of diagnostic labels on the affective responses of college students towards peers with 'Asperger's Syndrome' and 'Autism Spectrum Disorder'. Autism, 1362361315586721. 
Staff perception of challenging behaviour.

Bubb S. (2014). 'Winterbourne View - Time for Change' - retrieve on $30^{\text {th }}$ November 2014 from http://www.challengingbehaviour.org.uk/learning-disability-files/Bubbreport.pdf

Carter J. C., Capone G. T., Gray R. M., Cox C. S. \& Kaufmann W. E. (2007). Autistic-spectrum disorders in Down syndrome: further delineation and distinction from other behavioral abnormalities. American Journal of Medical Genetics Part B: Neuropsychiatric Genetics, 144, 87-94.

Cohen J. (1992). A power primer. Psychological Bulletin, 112, 155-159.

Dagnan D. \& Cairns M. (2005). Staff judgements of responsibility for the challenging behaviour of adults with intellectual disabilities. Journal of Intellectual Disabilities Research, 49, 95-101.

Dagnan D., Trower P. \& Smith R. (1998). Care staff responses to people with learning disabilities and challenging behaviour: a cognitive emotional analysis. The British Journal of Clinical Psychology, 37, 59- 68

de Ligt J., Willemsen M. H., van Bon B. W., Kleefstra T., Yntema H. G., Kroes T. \& Vissers L. E. (2012). Diagnostic exome sequencing in persons with severe intellectual disability. New England Journal of Medicine, 367, 1921-1929. 
Staff perception of challenging behaviour.

Emerson E, Baines S. The Estimated Prevalence of Autism Among Adults With Learning Disabilities in England. Lancaster, England: Learning Disabilities Observatory; 2010

Gibbs M. V. \& Thorpe J. G. (1983). Personality stereotype of noninstitutionalized Down syndrome children. American Journal of Mental Deficiency, 87, 601-605.

Hastings P. (1997a). Staff beliefs about challenging behaviours of children and adults with mental retardation. Clinical Psychology Review, 17, 775-790.

Hastings R. (1997b). Measuring staff perceptions of challenging behaviour: the Challenging Behaviour Attributions Scale (CHABA). Journal of Intellectual Disabilities, 41, 495-501.

Jones C. \& Hastings R. (2003). Staff reactions to self-injurious behaviours in learning disability services: attributions, emotional responses and helping. British Journal of Clinical Psychology 42, 189-203.

Link B., Cullen F., Struening E., Shrout P. \& B Dohrenwend. (1989). A Modified Labelling Theory Approach to Mental Disorders: An Empirical Assessment. American Sociological Review, 54, 400-423.

Lowe, K., Allen, D., Jones, E., Brophy, S., Moore, K., \& James, W. (2007).

Challenging behaviours: Prevalence and topographies. Journal of Intellectual Disability Research, 51(8), 625-636. 
Staff perception of challenging behaviour.

Lucas V., Collins S. \& Langdon P. (2009). The causal attributions of teaching staff towards children with intellectual disabilities: A comparison of 'vignettes' depicting challenging behaviour with 'real' incidents of challenging behaviour. Journal of Applied Research in Intellectual Disabilities, 22, 1-9.

Markham D. \& Trower P. (2003). The effects of the psychiatric label "borderline personality disorder" on nursing staff's perceptions and causal attributions for challenging behaviours. British Journal of Clinical Psychology, 42, 243-256.

Mills S. \& Rose J. (2011). The relationship between challenging behaviour, burnout and cognitive variables in staff working with people who have intellectual disabilities. Journal of Intellectual Disability Research, 55, 844-857.

Public Health England (2013) retrieved on 29 November 2014 from http://www.improvinghealthandlives.org.uk/publications/1241/

Rose J. (2011). How do staff psychological factors influence outcomes for people with developmental and intellectual disability in residential services? Current Opinion in Psychiatry, 24, 403-407.

Stanley B. \& Standen P. J. (2000). Carers' attributions for challenging behaviour. British Journal of Clinical Psychology, 39, 157-168.

Schneider W., Eschman A. \& Zuccolotto A. (2002). E-Prime: User's guide. Psychology Software Incorporated. 
Staff perception of challenging behaviour.

Tynan H. \& Allen D. (2002). The impact of service user cognitive level on carer attributions for aggressive behaviour. Journal of Applied Research in Intellectual Disabilities, 15, 213-223.

Wanless L. \& Jahoda A. (2002) Responses of staff towards people with mild to moderate intellectual disability who behave aggressively: a cognitive emotional analysis. Journal of Intellectual Disability Research, 46, 5007-5016.

Weiner B. (1985). An attributional theory of achievement, motivation and emotion. Psychological Reviews, 92, 547-573.

Willner P. \& Smith M. (2008). Attribution theory applied to helping behaviour towards people with intellectual disabilities who challenge. Journal of Applied Research in Intellectual Disabilities, 21, 150-155. 